\title{
Copper oxide nanoparticle doped bulk-heterojunction photovoltaic devices
}

\author{
E. Salim ${ }^{1}$, S.R. Bobbara ${ }^{2}$, A. Oraby ${ }^{1}$, J.M. Nunzi ${ }^{2,3}$ \\ ${ }^{1}$ Department of physics, Faculty of Science, Mansoura University, 35516, Egypt. \\ ${ }^{2}$ Department of Physics, Engineering Physics and Astronomy, Queen's University, Kingston, ON K7L 3N6, Canada. \\ ${ }^{3}$ Department of Chemistry, Queen's University, Kingston, ON K7L 3N6, Canada.
}

\begin{abstract}
Organic and metal oxide-based hybrid solar cells have drawn attention for their improved device performance along with mechanical stability and cost-effectiveness. We investigated the incorporation of various concentrations of copper oxide $(\mathrm{CuO})$ nanoparticles $(\mathrm{NPs})$ blended with poly 3-hexylthiophene: [6, 6]-phenyl$\mathrm{C}_{61}$-butyric methyl ester (P3HT:PCBM) bulk-heterojunction devices. With an optimum concentration of $\mathrm{CuO}$ NPs in P3HT: PCBM the devices power conversion efficiency is about $35 \%$ larger than without CuO NPs. The overall improvement in the photovoltaic properties of the device is attributed to the improved optical absorption, crystallinity and roughness of the photoactive layer confirmed by the AFM and XRD characteristics of the blended films. Beyond optimum nanoparticle concentration deteriorates the device performance from high trapped charge density as evidenced by steady-state current-voltage characteristics and charge-extraction-by-linearly-increasing-voltage (CELIV).
\end{abstract}

Keywords: Metal oxide nanoparticles; Copper oxide; P3HT; PCBM; Crystallinity, Mobility, Trapped charges. 


\section{Introduction}

Organic solar cells (OSCs) are gaining attention due to their low-cost, ease of fabrication, light-weight, flexibility and possible recyclability [1-5]. Research over last few decades aimed at enhancing the efficiency of OSCs, which usually have lower carrier mobility than their inorganic counterparts. While inorganic semiconductors are known for relatively high dielectric constant and charge mobility, their organic counterparts possess high absorption coefficients [6]. Thus, so-called hybrid solar cells (HSC) in which inorganic semiconducting nanoparticles are incorporated into organic matrices combine the advantages of both kinds of materials and achieve higher power conversion efficiency (PCE) while minimizing device fabrication costs [7]. Inorganic materials such as $\mathrm{ZnO}$ [8], $\mathrm{TiO}_{2}$ [9], $\mathrm{PbS}$ [10], $\mathrm{CdSe}$ [11], and $\mathrm{CuO}$ [12] have played a key role in performance improvement through increased exciton dissociation efficiency and enhanced light absorption [13-15]. Among these, $\mathrm{CuO}$ seems more promising candidate due to its low production-cost, nontoxicity, high optical absorption coefficient and $1.5 \mathrm{eV}$-band gap energy, which is close to the $1.4 \mathrm{eV}$ ideally desired energy band gap for solar cells [16,17]. In this work, we fabricated ternary hybrid inverted solar cells [18] containing P3HT as a donor material with PCBM as acceptor and p-type CuO nanoparticles [19]. The influence of $\mathrm{CuO}$ NPs incorporated inside the P3HT/PCBM matrix was studied using steady-state current-voltage $(\mathrm{J}-\mathrm{V})$ characteristics, UV-visible absorption, external quantum efficiency (EQE), atomic force (AFM) and scanning electron (SEM) microscopies. In addition, defect states from the nanoparticles and their effect on charge mobilities were studied using charge extraction by linearly increasing voltage (CELIV) technique.

\section{Experimental details}

\section{Materials}

Indium tin oxide (ITO) coated glass substrates with a sheet resistance of (20 - 25) $\Omega /$ sq were purchased from Lumtec, Taiwan. $\mathrm{CuO}$ nanoparticles of less than $50 \mathrm{~nm}$-diameter were purchased from Sigma-Aldrich. Zinc acetate dihydrate (99.9\% purity), 2-methoxyethanol (99.8 \% purity), and ethanolamine ( $99.5 \%$ purity) were purchased from Sigma-Aldrich. Regio-regular P3HT with 91-94\% regio-regularity and PCBM were 
purchased from Rieke Metals and SES Research, respectively. All materials were used without further purification.

\section{Device fabrication}

ITO glass substrates were sequentially rinsed in detergent, de-ionized water, acetone, and isopropyl alcohol in an ultrasonic bath for 10 minutes. The clean and dried substrates were treated with oxygen plasma for 12 minutes. ZnO sol-gel was prepared by mixing $500 \mathrm{mg}$ zinc acetate dihydrate with $140 \mathrm{mg}$ ethanolamine in 5 $\mathrm{ml}$ 2-methoxyethanol and stirred for 12 hours for hydrolysis reaction in the air [18]. The ZnO sol-gel was spin-coated at $3000 \mathrm{rpm}$ for $40 \mathrm{~s}$ on top of the ITO glass substrates. The samples were annealed at a fixed 150 ${ }^{\circ} \mathrm{C}$-temperature for 30 minutes and then allowed to cool down to room temperature. The P3HT-PCBM blend was prepared by mixing a 1:0.8-weight ratio of P3HT $(20 \mathrm{mg})$ : PCBM (16 mg) per $1 \mathrm{ml}$ of dichlorobenzene (DCB) and stirred for 12 hours at $60^{\circ} \mathrm{C}$. Different $\mathrm{CuO}$ NPs concentrations were dispersed in $0.5 \mathrm{ml}-\mathrm{DCB}$ and added to the P3HT: PCBM mixture. Weight ratios of the final P3HT: PCBM: CuO-NPs blends were 1:0.8:0.0, 1:0.8:0.01, 1:0.8:0.02, 1:0.8:0.03, 1:0.8:0.04 and 1:0.8:0.05 and they will be referred hereafter as $\mathrm{S}_{0}, \mathrm{~S}_{1}, \mathrm{~S}_{2}$, $\mathrm{S}_{3}, \mathrm{~S}_{4}$, and $\mathrm{S}_{5}$, respectively. The P3HT: PCBM: CuO NPs blends were spin-coated at $600 \mathrm{rpm}$ for one minute on top of a preheated layer of $\mathrm{ZnO}$ at $80{ }^{\circ} \mathrm{C}$, followed by heating at $150{ }^{\circ} \mathrm{C}$ for 10 minutes. Finally, $\mathrm{MoO}_{\mathrm{x}}$ and Ag thin-films, of thicknesses $7 \mathrm{~nm}$ and $100 \mathrm{~nm}$ respectively, were thermally evaporated forming an active device area of $0.06 \mathrm{~cm}^{2}$. The device structure with $\mathrm{ITO} / \mathrm{ZnO} / \mathrm{P} 3 \mathrm{HT}$ : $\mathrm{PCBM}$ : $\mathrm{CuO} / \mathrm{MoO}_{3} / \mathrm{Ag}$ layers is shown in Figure 1. The second type of device structure with ITO/ $\mathrm{ZnO} / \mathrm{P} 3 \mathrm{HT}$ : PCBM: $\mathrm{CuO} / \mathrm{ZnO} / \mathrm{Ag}$ layers was also fabricated with various concentrations of $\mathrm{CuO}$ NPs 1:0.8:0.0, 1:0.8:0.01, 1:0.8:0.02, 1:0.8:0.03, 1:0.8:0.04 and 1:0.8:0.05 to study the electron transport, and were labeled as $\mathrm{D}_{0}, \mathrm{D}_{1}, \mathrm{D}_{2}, \mathrm{D}_{3}, \mathrm{D}_{4}$, and $\mathrm{D}_{5}$, respectively. The $\mathrm{ZnO}$ top layer in these $\mathrm{D}_{\mathrm{n}}$-devices was spin coated at $3000 \mathrm{rpm}$ for $40 \mathrm{~s}$ on top of the active layer and was annealed at a $150{ }^{\circ} \mathrm{C}$ for 10 minutes. 


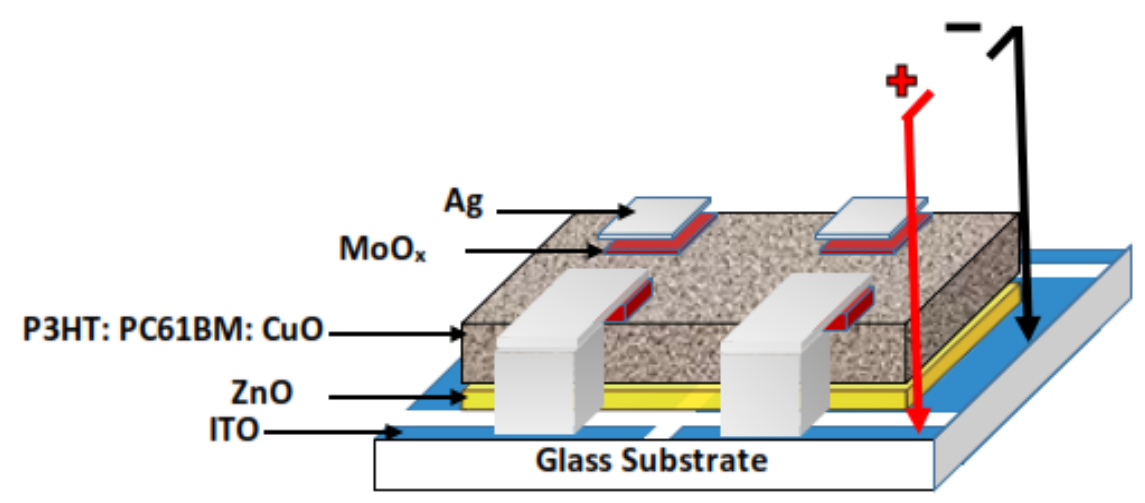

Fig. 1 Inverted HSC structure.

\section{Characterization Methods}

The inverted hybrid organic solar cells were characterized in the air without encapsulation. J-V characteristics were taken using a Keithley 2420 source meter unit under $100 \mathrm{~mW} / \mathrm{cm}^{2}$ AM 1.5G irradiation with a calibrated CT 100 AAA solar simulator. A Lambda 35 Perkin Elmer UV-Visible spectrophotometer was used for absorption spectra. EQE measurements were obtained using a QEX 7 PV system. The crystallinity of the active layers were studied using XRD with Co K-source at $40 \mathrm{kV}$ and $45 \mathrm{~mA}$ tube current. Morphology of the active layers was scanned using an Ambios technology Q 250 AFM. Surface and microstructure of the P3HT: PCBM with different CuO NP concentrations were examined using QUANTA FEG 250 SEM. Dektak step profiler was used to measure the $\mathrm{ZnO}$ and active layer thicknesses. Dielectric constant and charges extraction were quantified using CELIV. Figures $2 \mathrm{a}$ and $2 \mathrm{~b}$ illustrate a schematic of input ramp voltage and a typical CELIV output. In this technique, a linearly increasing voltage $V(t)=A t$, where $A$ is the ramp voltage towards reverse bias, is used to extract charge carrier density $(n)$ and mobility $(\mu)$ from the photoactive layer of thickness $(d)$ and dielectric permittivity $(\varepsilon)$. The charge mobility derived from CELIV is given by [19]:

$$
\mu=\frac{2 d^{2}}{3 A t_{\max }^{2}\left(1+0.36 \frac{\Delta j}{j_{0}}\right)}
$$


where $d$ is the active layer thickness, $A$ is the ramp rate of the applied voltage pulse, $t_{\max }$ is the time at which the current peak is observed in the transient, $\Delta j$ is the current maximum in the transient. $j_{0}=\varepsilon A / d$ is the displacement current used to measure the effective dielectric constant of the active layer.

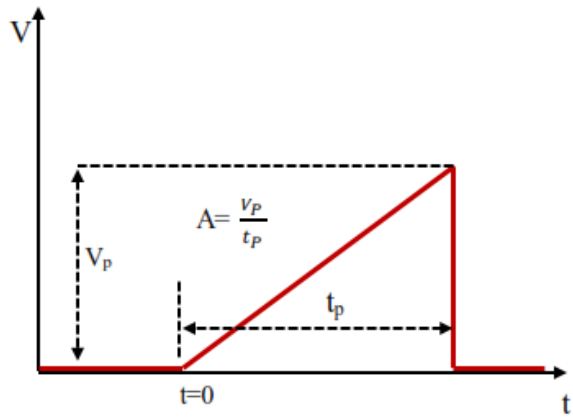

(a)

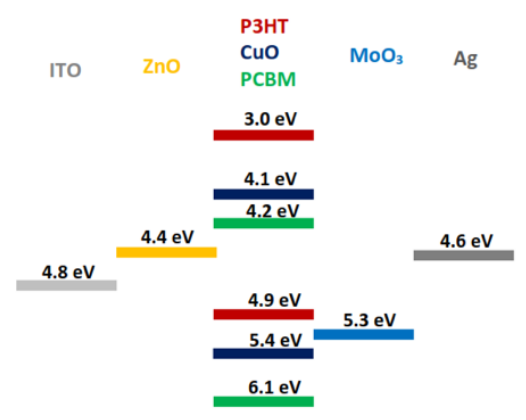

(c)

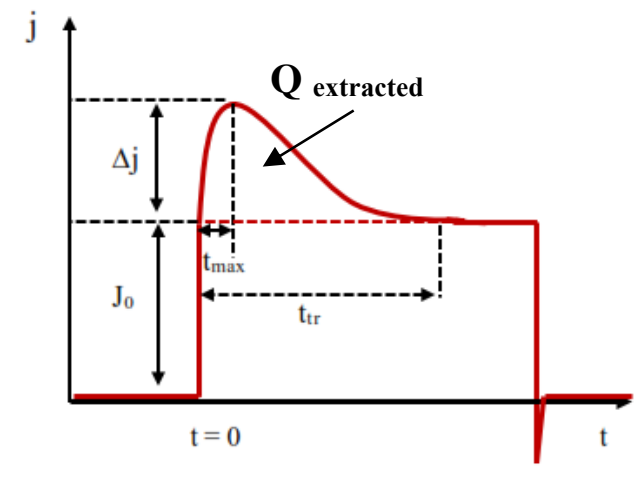

(b)

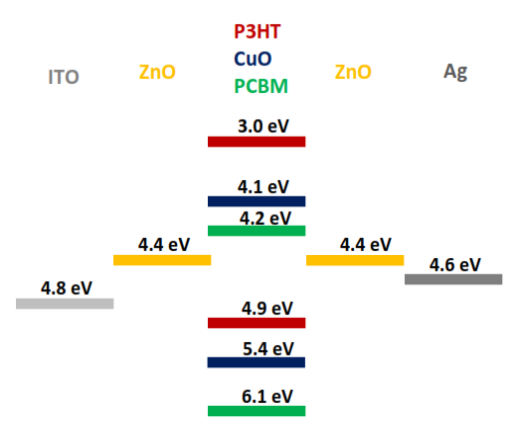

$\begin{array}{ll}7.8 \mathrm{eV} & 7.8 \mathrm{eV}\end{array}$

Fig. 2 (a) Voltage input, (b) typical current output in CELIV, energy levels of layers in the device-type c) ITO/ZnO/P3HT: $\mathrm{CuO}: \mathrm{PCBM} / \mathrm{MoO}_{\mathrm{x}} / \mathrm{Ag}$, and (d) ITO/ZnO/P3HT: $\mathrm{CuO}: \mathrm{PCBM} / \mathrm{ZnO} / \mathrm{Ag}$.

\section{Results and discussion}

Figure (2c) shows the energy level diagram of the inverted HSCs under study. The energetics favor photogenerated exciton dissociation at the P3HT/PCBM, P3HT/CuO and CuO/PCBM interfaces. The photogenerated electrons are transferred from the lowest unoccupied molecular orbital (LUMO) of the acceptor to the ITO via the conduction band of $\mathrm{ZnO}$, and the holes at the highest occupied molecular orbital (HOMO) of the donor are transported towards $\mathrm{MoO}_{3} / \mathrm{Ag}$. 
Figure 3 shows the J-V curves under dark and light conditions. The parameters that define the photovoltaic efficiency are listed in Table 1. The incorporation of $\mathrm{CuO}$ NPs in the active layer of the devices led to an increase in the short-circuit current $\left(\mathrm{J}_{\mathrm{SC}}\right)$ from $10.0 \mathrm{~mA} / \mathrm{cm}^{2}$ to a maximum of $11.4 \mathrm{~mA} / \mathrm{cm}^{2}$ and $\mathrm{FF}$ from 54 to $62 \%$, resulting in an increased PCE from $3.0 \%$ to $4.1 \%$. Both dark and light rectification improved with $\mathrm{CuO}$ NPs incorporation into the P3HT/PCBM blend. The PCE increase originates from the increase in $\mathrm{J}_{\mathrm{SC}}$, decrease in series resistance $\left(\mathrm{R}_{\mathrm{S}}\right)$ and higher shunt resistance $\left(\mathrm{R}_{\mathrm{SH}}\right)$ with the concentration of CuO NPs in the active layer up to the 1.00:0.80:0.03 ratio (S3). This improved performance is attributed to enhanced lightharvesting in the active layer. $\mathrm{V}_{\mathrm{OC}}$ increases from $0.56 \mathrm{~V}$ for $\mathrm{S}_{0}$ to $0.59 \mathrm{~V}$ for $\mathrm{S}_{3}$ owing to higher photon scattering off the nanoparticles, and hence higher absorption within the active medium supported also by the EQE measurements. The decrease in $\mathrm{R}_{\mathrm{S}}$ is correlated with the improved electron mobility as measured using CELIV. There is also an increase in the shunt resistance with increasing $\mathrm{CuO}$ NPs quantity in the photoactive layer. The increase in $\mathrm{R}_{\mathrm{SH}}$ from reduced leakage current and electron-hole recombination rate is possibly due to the formation of a metal oxide NP network aiding in efficient exciton dissociation. The $\mathrm{R}_{\mathrm{SH}}$ dropped past the $S_{3}$ for higher concentration of NPs. SEM images of $S_{0}, S_{3}$ and $S_{5}$ displayed in figure (5a-c) show that at higher NP concentration, there is particle agglomeration with diameters much larger than the average thickness of the active layer. This indicates that agglomerated particles are bridging between the cathode and anode contacts, thereby leading to reduced shunt resistance pathway for charge transport. 

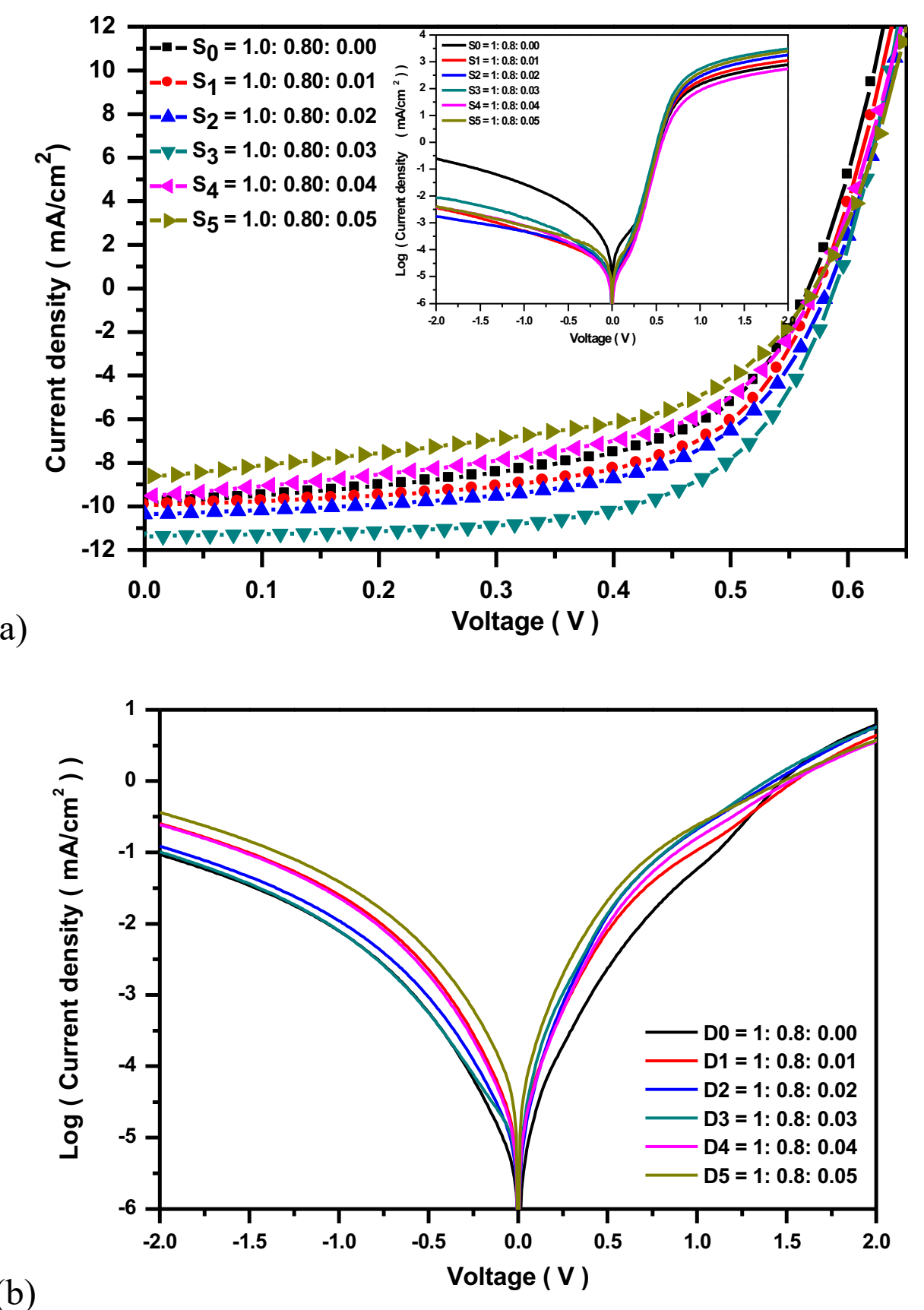

(b)

Fig. 3 (a) J-V characteristics under AM 1.5G standard light intensity, and (inset) dark log J -V characteristics of

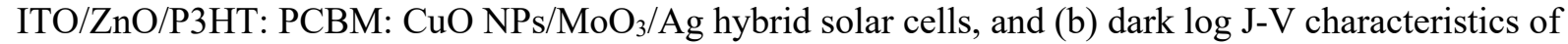
ITO/ZnO/P3HT: PCBM: CuO NPs/ZnO/Ag hybrid solar cells. 
Table 1: Electrical parameters extracted from the J-V curves in Figure 3(a).

\begin{tabular}{|c|c|c|c|c|c|c|}
\hline Device & $\begin{array}{l}\text { VOC } \\
(\mathrm{V})\end{array}$ & $\begin{array}{c}\mathrm{J}_{\mathrm{SC}} \\
\left(\mathrm{mA} / \mathrm{cm}^{2}\right)\end{array}$ & $\begin{array}{l}\text { FF } \\
(\%)\end{array}$ & $\begin{array}{c}\mathrm{R}_{\mathrm{S}} \\
\left(\Omega \mathrm{cm}^{2}\right)\end{array}$ & $\begin{array}{c}\mathbf{R}_{\mathrm{SH}} \\
\left(\Omega \mathrm{cm}^{2}\right)\end{array}$ & $\begin{array}{l}\text { PCE } \\
(\%)\end{array}$ \\
\hline $\mathbf{S}_{\mathbf{0}}$ & $0.56 \pm 0.02$ & $10.0 \pm 0.3$ & $54 \pm 3$ & 11 & 363 & $3.0 \pm 0.1$ \\
\hline $\mathbf{S}_{1}$ & $0.57 \pm 0.01$ & $10.2 \pm 0.1$ & $57 \pm 3$ & 9 & 546 & $3.3 \pm 0.1$ \\
\hline $\mathbf{S}_{2}$ & $0.58 \pm 0.00$ & $10.4 \pm 0.2$ & $60 \pm 01$ & 9 & 786 & $3.6 \pm 0.1$ \\
\hline $\mathbf{S}_{\mathbf{3}}$ & $0.59 \pm 0.01$ & $11.4 \pm 0.1$ & $61 \pm 2$ & 8 & 953 & $4.1 \pm 0.2$ \\
\hline $\mathbf{S}_{4}$ & $0.58 \pm 0.00$ & $9.4 \pm 1.6$ & $61 \pm 2$ & 9 & 677 & $3.3 \pm 0.3$ \\
\hline $\mathbf{S}_{5}$ & $0.58 \pm 0.00$ & $8.76 \pm 0.03$ & $58 \pm 1$ & 10 & 505 & $3.0 \pm 0.1$ \\
\hline
\end{tabular}

The hole mobility was estimated from the space-charge-limited current (SCLC) regime in the dark J-V characteristics. The Mott-Gurney's current-voltage relationship in the SCLC regime is given by [19]:

$$
\mathrm{J}=\frac{9}{8} \quad \varepsilon_{0} \varepsilon_{\mathrm{r}} \mu \frac{V^{2}}{d^{3}}
$$

where $\varepsilon_{\mathrm{o}}$ is the vacuum permittivity and $\varepsilon_{\mathrm{r}}$ is the dielectric constant of the photoactive layer, $\mu$ is the carrier mobility, and $d$ is the active layer thickness. The dielectric constants of the films were measured from the slope of the displacement currents $j_{0}=\varepsilon_{0} \varepsilon_{\mathrm{r}} A / d$ measured at different voltage ramp rates for each device summarized in Table 2. 


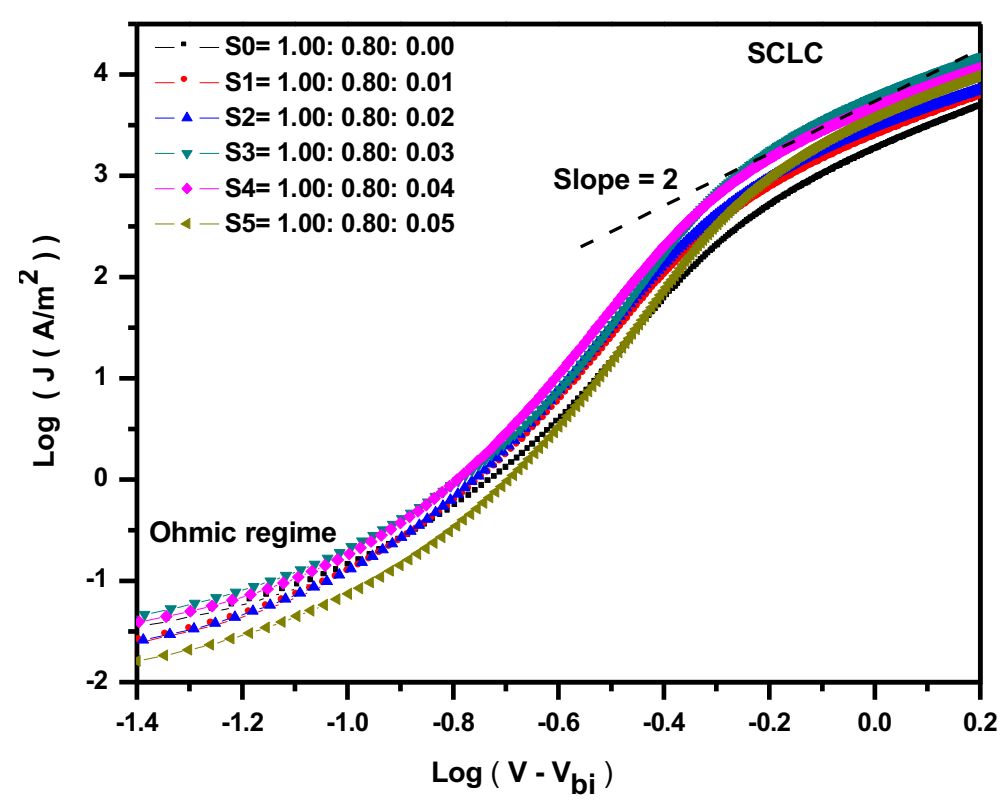

Fig. 4 Dark Log J - Log V characteristics of ITO/ZnO/P3HT: PCBM: CuO NPs/ $\mathrm{MoO}_{3} / \mathrm{Ag}$.

Figure 4 shows the dark J-V characteristics of all devices on a logarithmic scale. The charge mobilities, obtained from SCLC regime characterized by the slope of 2 in a $\log (\mathrm{J})-\log (\mathrm{V})$ plot are listed in Table 2 . The effective mobility increases from $4.40 \times 10^{-4} \mathrm{~cm}^{2} / \mathrm{V}$.s to $5.23 \times 10^{-4} \mathrm{~cm}^{2} / \mathrm{V}$.s with $\mathrm{CuO}$ NPs concentration increase, up to the 1.00:0.80:0.03 ratio $\left(\mathrm{S}_{3}\right)$. Further $\mathrm{CuO}$ NPs addition degrades the charge mobility.

Table 2: Dielectric constant of P3HT/PCBM/CuO NPs devices from CELIV and mobility from SCLC data.

\begin{tabular}{ccc}
\hline $\begin{array}{c}\text { Device structure } \\
\text { P3HT: PCBM: CuO NPs }\end{array}$ & Dielectric constant $\varepsilon_{\mathbf{r}}$ & $\begin{array}{c}\text { Mobility } \\
\boldsymbol{\mu}\left(\mathrm{cm}^{2} / \mathrm{Vs}\right)\end{array}$ \\
\hline$S_{0}$ & $3.18 \pm 0.01$ & $(4.40 \pm 0.07) \times 10^{-4}$ \\
\hline$S_{1}$ & $3.63 \pm 0.02$ & $(4.51 \pm 0.08) \times 10^{-4}$ \\
\hline$S_{2}$ & $4.00 \pm 0.12$ & $(4.70 \pm 0.05) \times 10^{-4}$ \\
\hline$S_{3}$ & $4.12 \pm 0.02$ & $(5.23 \pm 0.15) \times 10^{-4}$ \\
\hline$S_{4}$ & $4.15 \pm 0.09$ & $(4.34 \pm 0.15) \times 10^{-4}$ \\
\hline$S_{5}$ & $4.40 \pm 0.03$ & $(3.33 \pm 0.24) \times 10^{-4}$ \\
\hline
\end{tabular}


Figure (5a-c) displays the typical SEM images of the P3HT: PCBM and P3HT: PCBM with various concentration of $\mathrm{CuO}$ NPs (1: 0.8: 0, 1: 0.8: 0.03 and 1: 0.8: 0.05). Figure 5a shows the smooth surface morphology of the $\mathrm{CuO}$ NPs free active layer (1:0.8:0.00). Further CuO NPs incorporation in the P3HT: PCBM blend shows large aggregates distributed randomly on the surface of the blend as in figure (5c).



(a)

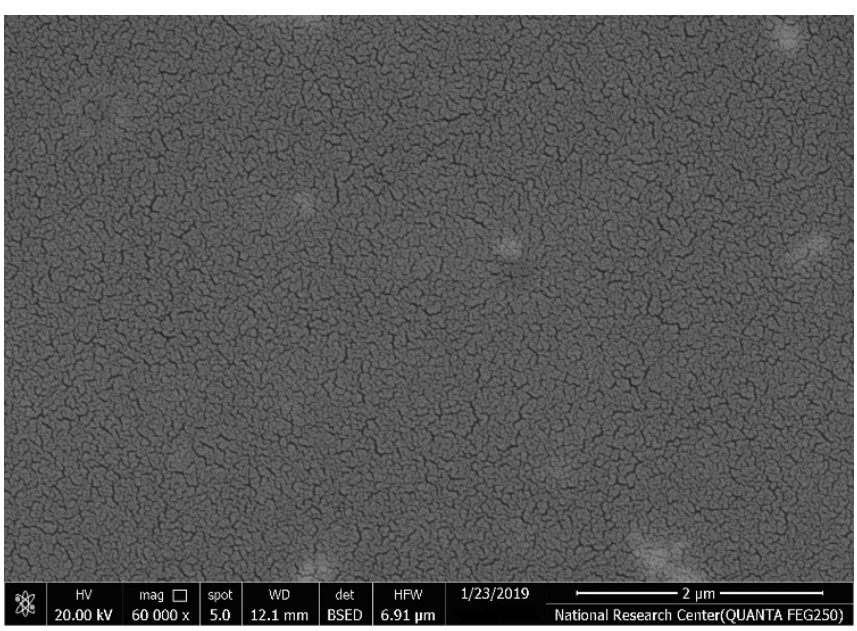

(b)

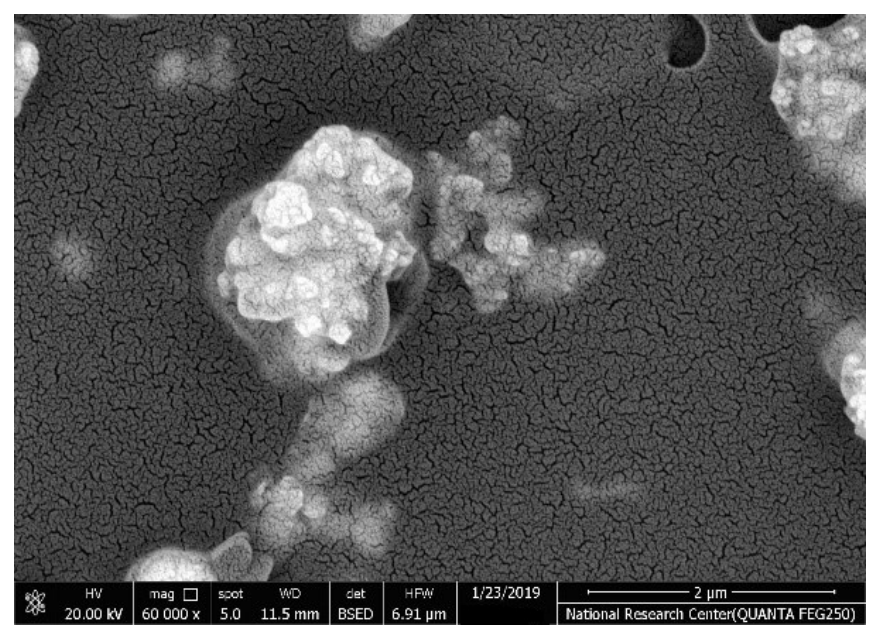

(c)

Fig. 5 SEM images of P3HT: PCBM: CuO NPs at ratios (a) 1:0.8:0.00, (b) 1:0.8:0.03 and (c) 1:0.8:0.05. 


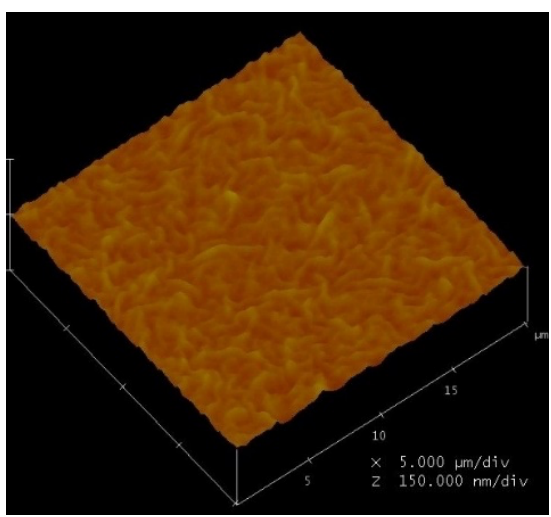

(a)

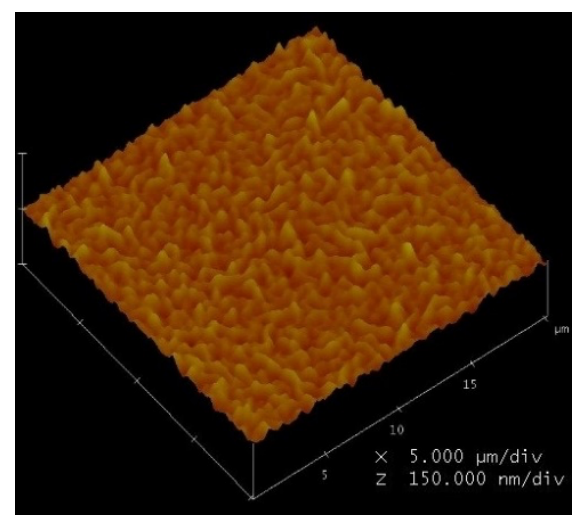

(d)

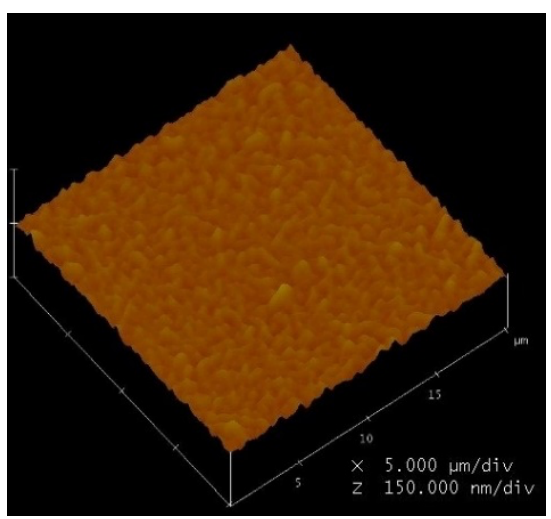

(b)



(e)

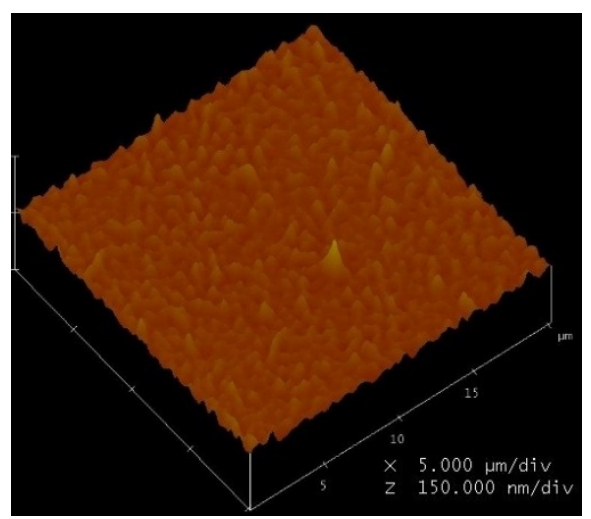

(c)

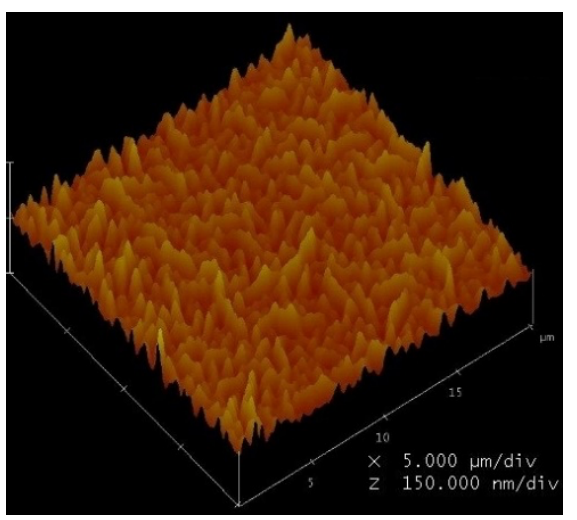

(f)

Fig.6 AFM images of P3HT: PCBM: CuO NP blended films with P3HT: PCBM: CuO NP ratios (a) 1.00:0.80:0.00, (b) 1.00:0.80:0.01, (c) 1.00:0.80:0.02, (d) 1.00:0.80:0.03, (e) 1.00:0.80:0.04, and (f) 1.00:0.80:0.05.

Figure 6 shows the AFM surface topography of $\mathrm{P} 3 \mathrm{HT} / \mathrm{PCBM}$ with various $\mathrm{CuO}$ NP concentrations. The rootmean-square (rms) roughness increased from $3.5 \mathrm{~nm}$ without $\mathrm{CuO}$ NPs to $9.4 \mathrm{~nm}$ maximum with maximum $\mathrm{CuO}$ NP loading $\left(\mathrm{S}_{5}\right)$. The rms roughness is $6.1 \mathrm{~nm}$ for the optimum 1.00:0.80:0.03 ratio sample $\mathrm{S}_{3}$.

Figure 7 shows a significant increase in the absorption and redshift of its maximum with increasing $\mathrm{CuO} \mathrm{NP}$ concentration. The ternary-blend films exhibit an absorption peak at $330 \mathrm{~nm}$ corresponding to PCBM absorption and three shoulders at 500,560, and $610 \mathrm{~nm}$, which are ascribed to the crystalline $\pi$-stacking structure of P3HT [20]. The increase in absorption (i.e. reduced transmission) with CuO NPs proportion in the $\mathrm{P} 3 \mathrm{HT} / \mathrm{PCBM}$ is possibly from high surface roughness that increases light scattering within the photoactive layer [21]. 


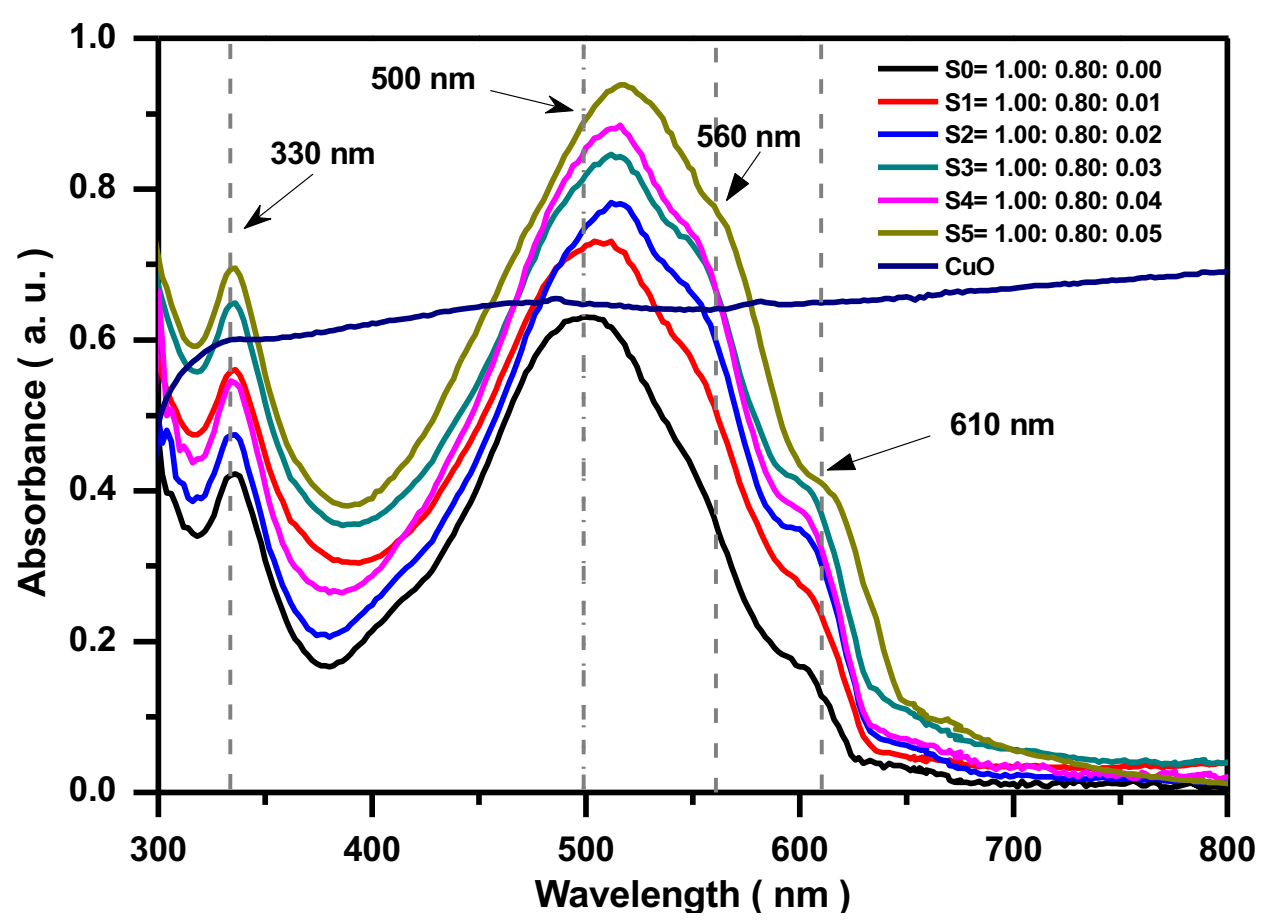

Fig. 7 UV- Visible absorption spectra of $\mathrm{P} 3 \mathrm{HT} / \mathrm{PCBM}$ with various concentrations of CuO NPs.

Figure 8 shows the EQE for solar cells with various $\mathrm{CuO}$ NP amounts. The EQE increases with $\mathrm{CuO}$ NP addition across the wavelengths ranging from 400 to $600 \mathrm{~nm}$, following the absorbance trend. While the EQE correlates with optical absorption spectrum, beyond the optimum concentration it doesn't follow the same trend as PCE. The primary reason for this difference is the possibility of non-geminate in addition to geminate recombination at the maximum power output point taken in calculating PCE, whereas in EQE measurements geminate recombination is known to be the dominant loss channel [22]. 


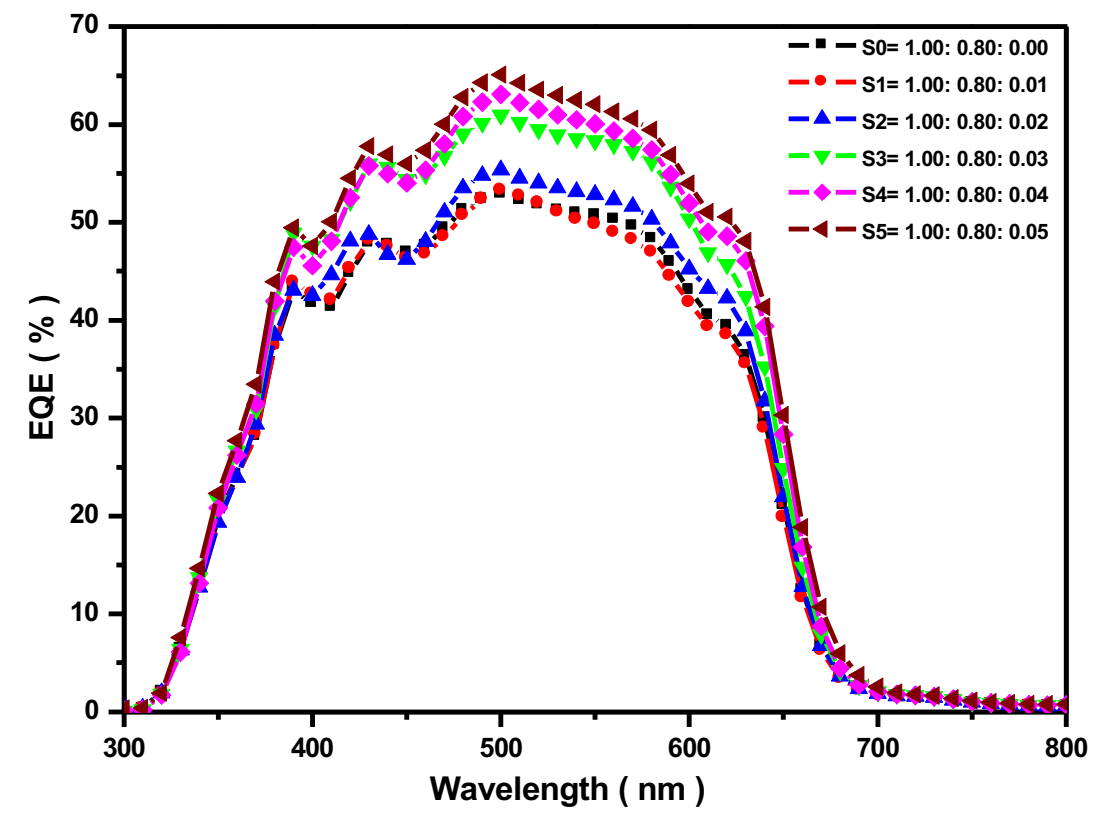

Fig. 8 The external quantum efficiency of ITO/ZnO/P3HT:PCBM: $\mathrm{CuO} / \mathrm{MoO}_{3} / \mathrm{Ag}$ device.

Figure 9 shows the XRD spectrum emphasizing the improvement in crystallinity of P3HT with CuO NP in the blended films. The peak at about 6.5 degrees of $2 \theta$ diffraction angle corresponds to the P3HT crystallinity [23]. The full width at half maximum (FWHM) reduces and the peak intensity increases with increasing $\mathrm{CuO}$ NP concentration. The P3HT crystallinity increase may be attributed to $\mathrm{CuO}$ NPs supporting the formation of crystalline phases for P3HT chains in the blend, in accordance with previously reported work [24]. The increase in crystallinity may partly be responsible for the increased PCE.

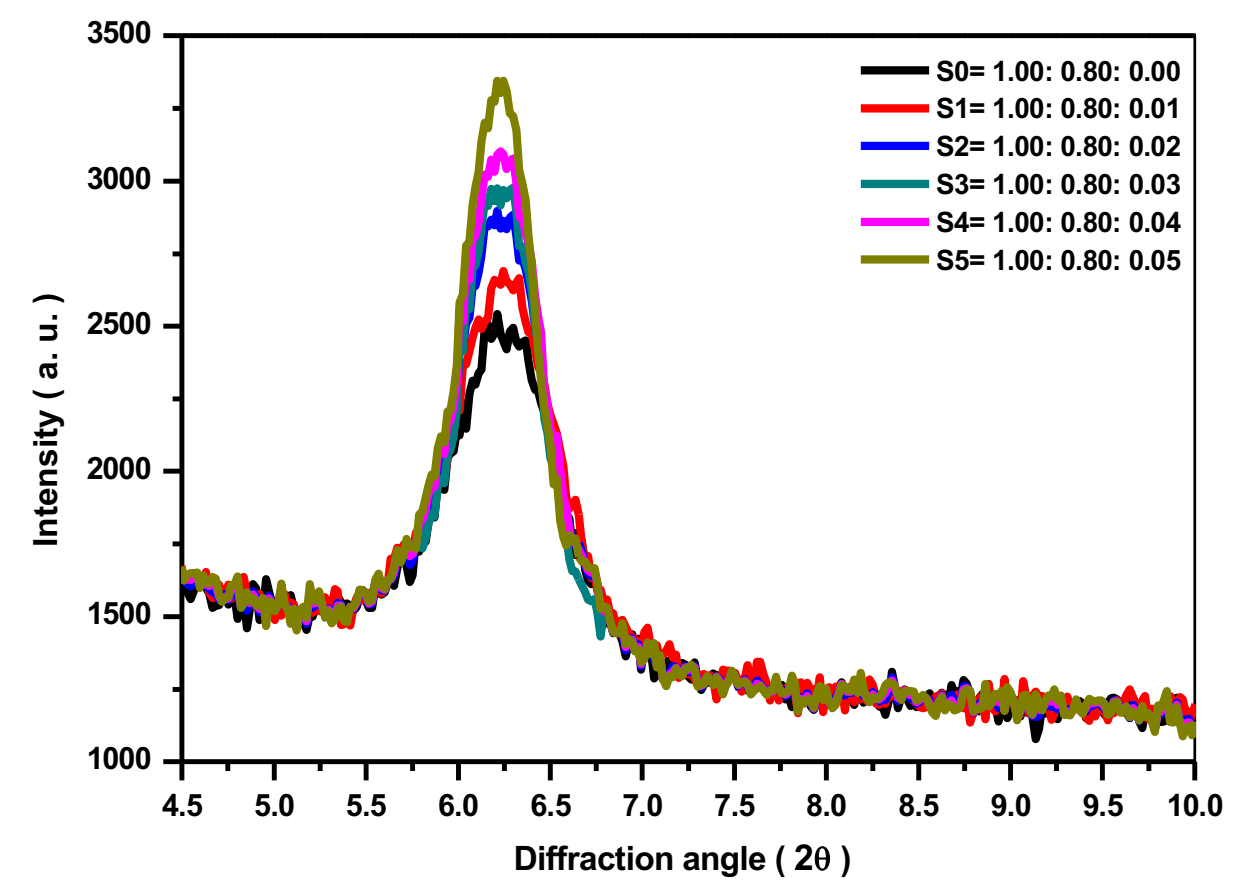

Fig.9 XRD of P3HT/PCBM with CuO NPs. 
CELIV was used to evaluate the mobility $(\mu)$ and charge carrier density $(n)$ within the devices [25]. Figures 10(a) and 10(b) show the dark CELIV transients of the two types of devices, named as S and D, at different offset voltage. The S-devices with structure ITO/ ZnO/ P3HT: PCBM: CuO NPs/ $\mathrm{MoO}_{\mathrm{x}} / \mathrm{Ag}$ and the D-devices with structure ITO/ ZnO/ P3HT: PCBM: $\mathrm{CuO} \mathrm{NPs/} \mathrm{ZnO/} \mathrm{Ag.} \mathrm{The} \mathrm{intention} \mathrm{here} \mathrm{is} \mathrm{to} \mathrm{identify} \mathrm{the} \mathrm{role} \mathrm{of}$ different types of charge carriers extracted using CELIV. The ramp voltage was fixed at $6.6 \times 10^{3} \mathrm{Vs}^{-1}$ in all studies. In the S-devices, $\mathrm{ZnO}$ plays the role of hole blocking layer (HBL) as well as an electron transport layer, while $\mathrm{MoO}_{\mathrm{x}}$ layer aids in forming an ohmic contact for holes across the active layer and Ag contact. Thereby making it predominantly a hole-only device at small forward bias voltages. At higher offset voltages electron-injection into the LUMO levels of the active media is also facilitated. During the ramp voltage sweep, free and trapped charges from the device are extracted. Figure 10 (a) shows two distinct CELIV peaks from S-devices: a sharper peak for the higher offset voltages $>0.4 \mathrm{~V}$, which can be assigned to the high-speed free electron and hole extraction, and a broader peak indicating the extraction of the slower deep trapped electrons and holes. Evidence for electron-only injection into the D-device is supported by the dark J-V characteristics in figure 3(b), which displays poor current rectification in either forward or reverse bias, i.e. the electroninjection occurs from both ITO and Ag contacts. Although rectification in the D-devices is quite low compared to the S-Devices, which is one of the primary requirements to perform CELIV, the rectification was sufficient to perform CELIV studies on the D-devices. Figure 10 (b) shows the electron extracted from the D-devices incorporating various concentration of CuO NPs. Unlike in the S-devices, there is no sharp CELIV peak seen in the D-devices indicating there is only one type of charge (electrons) participating in the trap-filling and extraction process. Increase in the trap density from nanoparticles slows down the switching speed of the diodes, as shown in the inset of figure 10(c) where ramp voltage drops back to the initial offset voltage level. Figure $10(\mathrm{~d})$ shows the density of extracted charge carriers from $\mathrm{D}$ and $\mathrm{S}$ type devices at $0.3 \mathrm{~V}$ for various $\mathrm{CuO} \mathrm{NP}$ concentrations in the device. The density of extracted electrons and holes increases with the incorporation of $\mathrm{CuO}$ NPs emphasizing the role of NPs in increasing trap state density. 


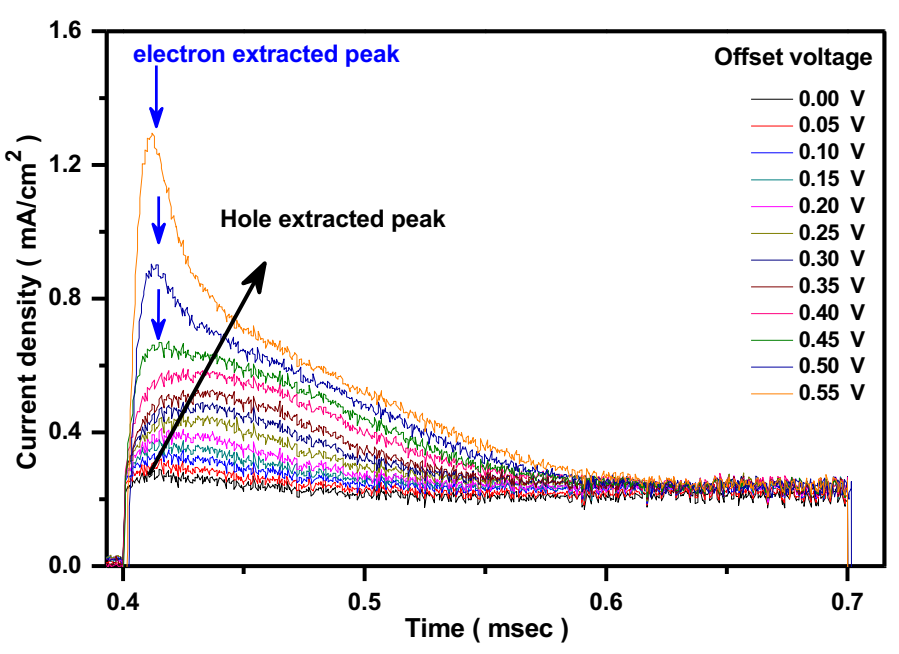

(a)

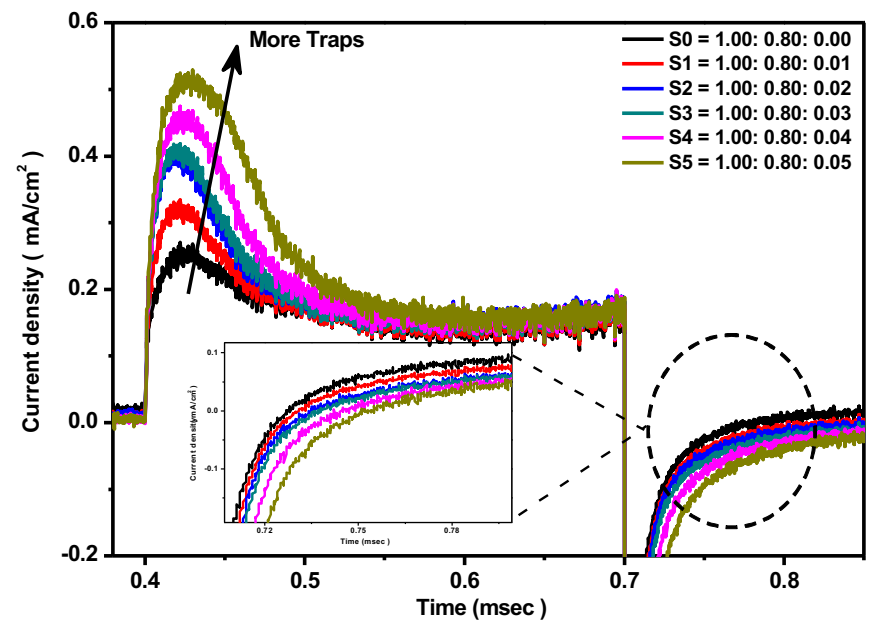

(c)

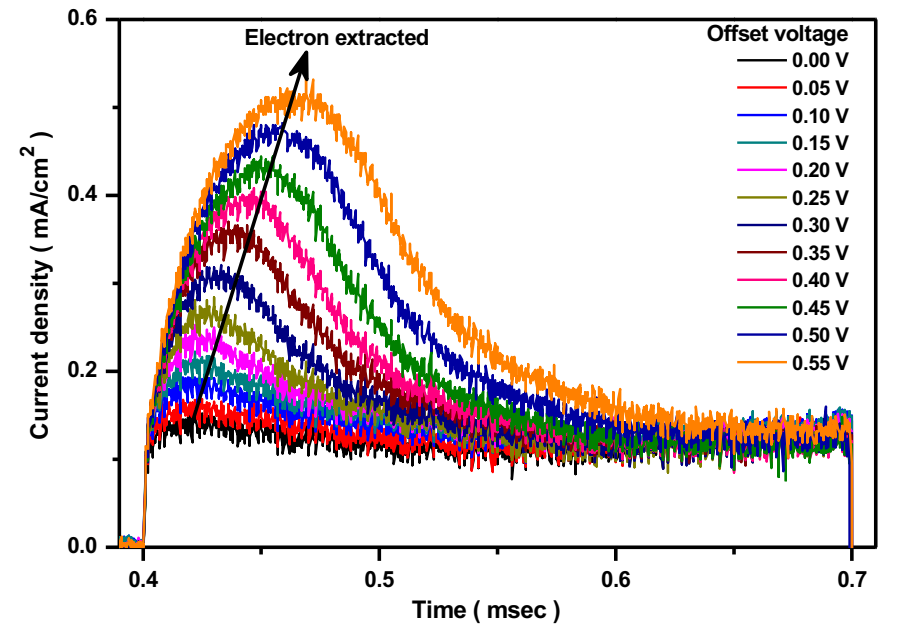

(b)

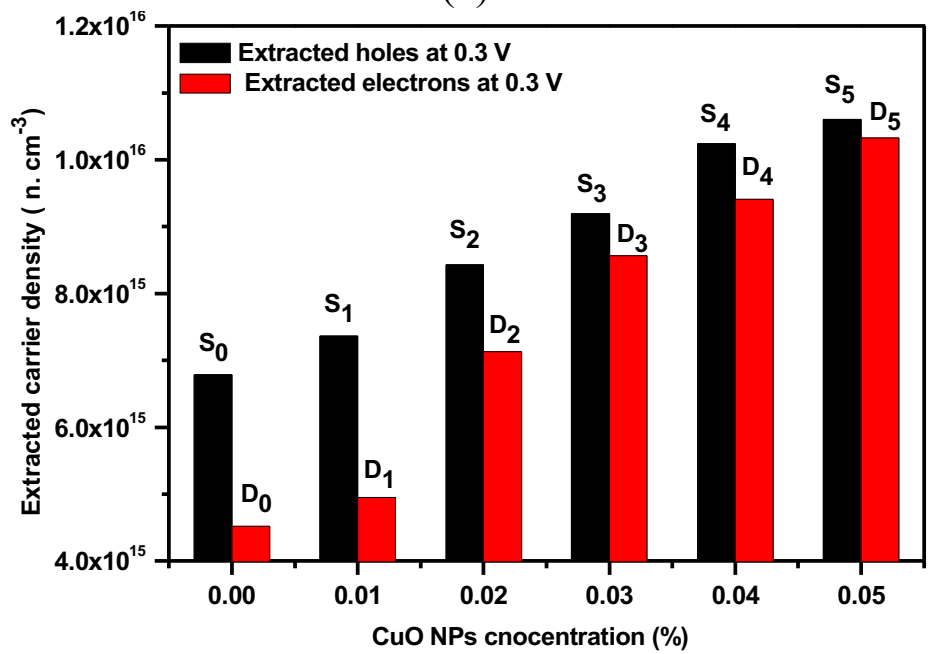

(d)

Fig.10 CELIV transients (a) ITO/ ZnO/P3HT: PCBM: $\mathrm{CuO}$ NPs/ $\mathrm{MoO}_{3} / \mathrm{Ag}$ and (b) ITO/ ZnO/P3HT: PCBM: $\mathrm{CuO} / \mathrm{ZnO} / \mathrm{Ag}$ of device structure at different offset Voltages, (c) CELIV transient (inset; switching time ) of ITO/ $\mathrm{ZnO} / \mathrm{P} 3 \mathrm{HT}$ : PCBM: $\mathrm{CuO} \mathrm{NPs} / \mathrm{MoO}_{3} / \mathrm{Ag}$ devices at $0.3 \mathrm{~V}$ offset voltage, and (d) extracted holes (black columns) and extracted electrons (red columns) densities at $0.3 \mathrm{~V}$ offset versus $\mathrm{CuO}$ NPs concentration. 


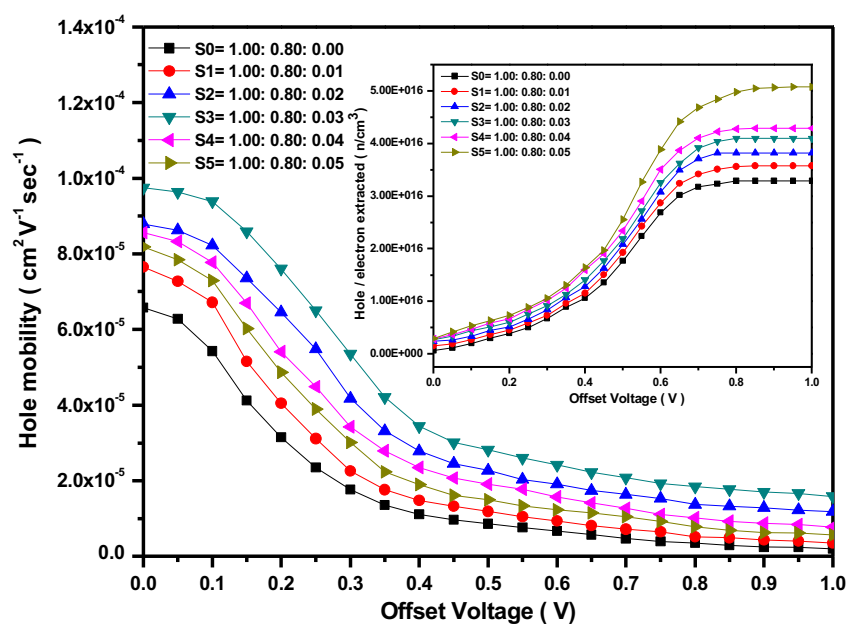

(a)



(b)

Fig.11 Mobilities and carrier densities (inset) extracted from CELIV measurements at the same $0.66 \times 10^{4} \mathrm{Vs}^{-1} \mathrm{ramp}$ voltage for different initial offset voltages. (a) extracted holes in ITO/ $\mathrm{ZnO} / \mathrm{P} 3 \mathrm{HT}: \mathrm{PCBM}: \mathrm{CuO} / \mathrm{MoO}_{3} / \mathrm{Ag}$ devices, and (b) extracted electrons in ITO/ $\mathrm{ZnO} / \mathrm{P} 3 \mathrm{HT}$ : PCBM: $\mathrm{CuO} / \mathrm{ZnO} / \mathrm{Ag}$ devices.

Equation (1) was used to calculate the hole (extracted hole peaks of S-devices indicated in figure 10(a)) and electron mobilities of D-devices at different offset voltages in Figure 11 (a) and (b), respectively. The carrier densities in the inset of Figure 11 (a) and 11(b) were obtained from integrating the CELIV transients. Mobility of both carriers increases with $\mathrm{CuO} \mathrm{NP}$ addition in the devices till the 1.00:0.80:0.03 ratio in $\mathrm{S}_{3}$. However, both mobilities decrease beyond this ratio. This mobility decrease at higher $\mathrm{CuO}$ NP ratio coincides with the increase in carrier trap state density. With more dopants into the devices, carriers in deeper states are extracted slower and take more time to thermalize than carriers in shallow states, Thus, the mobilities decrease with increasing the initial offset voltage.

\section{Conclusion}

In the present work, we investigated the effect of incorporating $\mathrm{CuO}$ NPs into the bulk of P3HT: PCBM in an attempt to reduce and replace the acceptor molecules. At optimum concentration of the CuO NPs the PCE of P3HT: PCBM cells increases from $3.0 \%$ to $4.1 \%$. The improvement reverses at higher $\mathrm{CuO} \mathrm{NP}$ concentrations owing to traps that favor charge recombination within the device. The improved efficiency with nanoparticle concentration goes with increased roughness which scatters light into the cells, increased crystallinity which improves mobility and increased dielectric constant which reduces charge recombination 
probability [26]. The effective SCLC mobility increases from $4.40 \times 10^{-4} \mathrm{~cm}^{2} / \mathrm{Vs}$ to $5.23 \times 10^{-4} \mathrm{~cm}^{2} / \mathrm{Vs}$ with $\mathrm{CuO}$ NP concentration increase. The increased trap density with nanoparticles increases the probability of charge recombination by slowing down their extraction, which justifies the existence of an optimum $3 \%$ NP concentration for the photovoltaic efficiency. The present study provides justification to recent experiments in which metal oxide NPs systematically improved the PCE of P3HT: PCBM bulk-heterojunction solar cells [27].

\section{Acknowledgments}

We dedicate our research to Dr. Erwin Buncel. Authors would like to acknowledge financial support from the Egyptian Government for 2 years joint scholarship at Queen's University. Research was funded by the National Science Research Council of Canada Discovery Grants (RGPIN-2015-05485).

\section{References}

[1] G. Yu, J. Gao, J.C. Hummelen, F. Wudl, A.J. Heeger, Polymer Photovoltaic Cells : Enhanced Efficiencies via a Network of Internal Donor- Acceptor Heterojunctions, Science 270 (1995) 1789-1791. doi:

10.1126/science.270.5243.1789

[2] M.R. Lee, R.D. Eckert, K. Forberich, G. Dennler, C.J. Brabec, R. a Gaudiana, Solar power wires based on organic photovoltaic materials., Science 324 (2009) 232-235. doi: 10.1126/science.1168539

[3] S. Günes, H. Neugebauer, N.S. Sariciftci, Conjugated polymer-based organic solar cells, Chem. Rev. 107 (2007) 1324-1338. doi: 10.1021/cr050149z

[4] J.Y. Kim, K. Lee, N.E. Coates, D. Moses, T. Nguyen, M. Dante, A.J. Heeger, Efficient Tandem Ploymer Solar Cells Fabricated by All-Solution Processing, Science 317 (2007) 222-225. doi: 10.1126/science.1141711

[5] F.C. Krebs, J. Alstrup, H. Spanggaard, K. Larsen, E. Kold, Production of large-area polymer solar cells by industrial silk screen printing, lifetime considerations and lamination with polyethyleneterephthalate, Sol. Energy Mater. Sol. Cells 83 (2004) 293-300. doi: 10.1016/j.solmat.2004.02.031

[6] C.H. Kim, S.H. Cha, S.C. Kim, M. Song, J. Lee, W.S. Shin, S.J. Moon, J.H. Bahng, N.A. Kotov, S.H. Jin, Silver nanowire embedded in P3HT:PCBM for high-efficiency hybrid photovoltaic device applications, ACS Nano. 5 (2011) 3319-3325. doi: 10.1021/nn200469d

[7] Y. Huang, D.R. Paul, Effect of MolecularWeight and Temperature on Physical Aging of ThinGlassy Poly(2,6dimethyl-1,4-phenylene oxide) Films, J. Polym. Sci. Part B Polym. Phys. 45 (2007) 1390-1398. doi:

10.1002/polb.21173

[8] W.J.E. Beek, M.M. Wienk, R.A.J. Janssen, Efficient hybrid solar cells from zinc oxide nanoparticles and a conjugated polymer, Adv. Mater. 16 (2004) 1009-1013. doi: 10.1002/adma.200306659

[9] C.Y. Kwong, W.C.H. Choy, A.B. Djuri i, P.C. Chui, K.W. Cheng, W.K. Chan, Poly(3-hexylthiophene): $\mathrm{TiO}_{2}$ nanocomposites for solar cell applications, Nanotechnology. 15 (2004) 1156-1161. doi: 10.1088/0957-4484/15/9/008 
[10] S. Zhang, P.W. Cyr, S.A. McDonald, G. Konstantatos, E.H. Sargent, Enhanced infrared photovoltaic efficiency in $\mathrm{PbS}$ nanocrystal/semiconducting polymer composites: 600 -fold increase in maximum power output via control of the ligand barrier, Appl. Phys. Lett. 87 (2005) 233101. doi: 10.1063/1.2137895

[11] B. Sun, H.J. Snaith, A.S. Dhoot, S. Westenhoff, N.C. Greenham, Vertically segregated hybrid blends for photovoltaic devices with improved efficiency, J. Appl. Phys. 97 (2005) 014914. doi: 10.1063/1.1804613

[12] A.P. Wanninayake, S. Gunashekar, S. Li, B.C. Church, N. Abu-Zahra, Performance enhancement of polymer solar cells using copper oxide nanoparticles, Semicond. Sci. Technol. 30 (2015) 064004. doi: 10.1088/0268-

$1242 / 30 / 6 / 064004$

[13] H.A. Atwater, A. Polman, Plasmonics for improved photovoltaic devices, Nat. Mater. 9 (2010) 205-213. doi: $10.1038 /$ nmat2629

[14] D. Qu, F. Liu, J. Yu, W. Xie, Q. Xu, X. Li, Y. Huang, Plasmonic core-shell gold nanoparticle enhanced optical absorption in photovoltaic devices, Appl. Phys. Lett. 98 (2011) 113119. doi: 10.1063/1.3559225

[15] E.A. Parlak, T. AslTumay, N. Tore, Ş. Saroğlan, P. Kavak, F. Türksoy, Efficiency improvement of PCDTBT solar cells with silver nanoparticles, Sol. Energy Mater. Sol. Cells 110 (2013) 58-62. doi:

10.1016/j.solmat.2012.12.002

[16] H. Kidowaki, T. Oku, T. Akiyama, Fabrication and characterization of CuO/ZnO solar cells, J. Phys. Conf. Ser. 352 (2012) 012022. doi: 10.1088/1742-6596/352/1/012022

[17] A. Mittiga, E. Salza, F. Sarto, M. Tucci, R. Vasanthi, Heterojunction solar cell with $2 \%$ efficiency based on a $\mathrm{Cu}_{2} \mathrm{O}$ substrate, Appl. Phys. Lett. 88 (2006) 163502. doi: 10.1063/1.2194315

[18] N. Sekine, C.H. Chou, W.L. Kwan, Y. Yang, ZnO nano-ridge structure and its application in inverted polymer solar cell, Org. Electron. 10 (2009) 1473-1477. doi: 10.1016/j.orgel.2009.08.011

[19] P.N. Murgatroyd, Theory of space-charge-limited current enhanced by Frenkel effect, J. Phys. D. Appl. Phys. 3 (1970) 151-156. doi: 10.1088/0022-3727/3/2/308

[20] Y. Chang, L. Wang, Efficient Poly ( 3-hexylthiophene ) -Based Bulk Heterojunction Solar Cells Fabricated by an Annealing-Free Approach, J. Phys. Chem. C. 112 (2008) 17716-17720. doi: 10.1021/jp804909a

[21] M. Park, B.D. Chin, J.W. Yu, M.S. Chun, S.H. Han, Enhanced photocurrent and efficiency of poly(3hexylthiophene)/fullerene photovoltaic devices by the incorporation of gold nanoparticles, J. Ind. Eng. Chem. 14 (2008) 382-386. doi: 10.1016/j.jiec.2008.01.014

[22] D. Credgington, F.C. Jamieson, B. Walker, T. Nguyen, J.R. Durrant, Quantification of Geminate and NonGeminate Recombination Losses within a Solution-Processed Small-Molecule Bulk Heterojunction Solar Cell, $A d v$. Mater. 24 (2012) 2135-2141. doi: 10.1002/adma.201104738

[23] P. Aruna, C.M. Joseph, Annealing effects on the electrical properties of spin coated poly (3-hexylthiophene ) (P3HT) thin films, Mater. Sci. Semicond. Process. 61 (2017) 39-44. doi: 10.1016/j.mssp.2016.12.041

[24] M. Ikram, R. Murray, A. Hussain, S. Ali, S. Ismat Shah, Hybrid organic solar cells using both ZnO and PCBM as electron acceptor materials, Mater. Sci. Eng. B 189 (2014) 64-69. doi: 10.1016/j.mseb.2014.08.005

[25] J. Kniepert, M. Schubert, J.C. Blakesley, D. Neher, Photogeneration and Recombination in P3HT/PCBM Solar Cells Probed by Time-Delayed Collection Field Experiments, J. Phys. Chem. Lett. 2 (2011) 700-705. doi: $10.1021 / \mathrm{jz} 200155 \mathrm{~b}$

[26] R. Wang, X. Zhang, D. Zhang, Q. Zhou, R. Wang, J. Zhou, J. Wang, Fluorination with an enlarged dielectric constant prompts charge separation and reduces bimolecular recombination in non-fullerene organic solar cells with a high fill factor and efficiency > 13\%, Nano Energy. 56 (2018) 494-501. doi:10.1016/j.nanoen.2018.11.067

[27] M. Ikram, M. Imran, J.M. Nunzi, S.R. Bobbara, S. Ali, Efficient and low cost inverted hybrid bulk heterojunction solar cells, J. Renew. Sust. Energy 7 (2015) 043148. doi: 10.1063/1.4929603 